\title{
Adult Intussusception in Patients with Peutz-Jeghers Syndrome: Case Series and Review of Literature
}

\author{
Mohamed A. Mlees, Tamer A. El-Bakary*, Magdy M. El-Gendy, Ahmed A. Darwish \\ Department of General Surgery, Tanta University Hospital, Tanta, Egypt \\ Email: *telbakary@yahoo.com
}

How to cite this paper: Mlees, M.A., El-Bakary, T.A., El-Gendy, M.M. and Darwish, A.A. (2017) Adult Intussusception in Patients with Peutz-Jeghers Syndrome: Case Series and Review of Literature. Surgical Science, 8, 118-132.

https://doi.org/10.4236/ss.2017.82014

Received: January 19, 2017

Accepted: February 21, 2017

Published: February 24, 2017

Copyright $\odot 2017$ by authors and Scientific Research Publishing Inc. This work is licensed under the Creative Commons Attribution International License (CC BY 4.0).

http://creativecommons.org/licenses/by/4.0/

(c) (i) Open Access

\begin{abstract}
Background: Peutz-Jeghers syndrome (PJS) is a rare autosomal dominant disorder characterized by gastrointestinal hamartomatous polyps and mucocutaneous pigmentations in the mouth, facial skin, hands \& feet. Small bowel obstruction, intussusception, bleeding, intestinal and extra-intestinal malignancies are the major complications of PJS. The aim of this study is to analyze the clinical characteristics, preoperative diagnosis, and surgical management of PJS associated-intussusception in adults. Patients and Methods: This study included 5 cases with intussusception in PJS patients presented to Surgical Oncology Unit, General Surgery Department, Tanta University Hospital, Egypt and Hamad General Hospital, Hamad Medical Corporation, Qatar, between October 2011 and March 2016. Patients' demographics were collected. After thorough clinical examination, abdominal X-ray, US, \& CT scan were done. All the patients were submitted to midline laparotomy with resection anastomosis of the affected bowel segment. Results: The mean age was 28.4 years. Female: male ratio was 3:2. Abdominal pain was the most common presenting complaint with or without intestinal obstruction manifestations. Palpable abdominal mass was found in 3 patients (60\%). Intussusception was proved pre-operatively in all the cases by abdominal ultrasound and CT scan. The intussusception was found in the jejunum in 3 patients, ileum in 1 patient, \& in 1 patient, there was double intussusception (one jejunal \& one ileo-cecal). Histopathological examination revealed the presence of typical Peutz-Jeghers hamartomatous polyp. No morbidity or mortality was reported at a mean follow-up period of 32 months. Conclusion: Family history, physical examination, abdominal ultrasound and CT scan were important in the diagnosis of acute intussusception caused by PJS. Surgical management of PJS associated intussusception is the recommended treatment to relieve patient's symptoms and to avoid missing underlying malignancy. Patients with PJS should be followed up throughout their lives because of the increased risk of malignant changes.
\end{abstract}




\section{Keywords}

Peutz-Jeghers Syndrome, Intussusception, Hamartomatous Polyp

\section{Introduction}

Peutz-Jeghers syndrome (PJS) is a rare inherited autosomal dominant disorder, first described by Peutz in 1921 and Jeghers in 1944 and 1949. It is seen equally in both male and female patients with no racial predominance and usually diagnosed during childhood or early adulthood [1] [2]. Peutz-Jeghers syndrome is characterized by gastrointestinal hamartomatous polyps and mucocutaneous pigmentations in the oral cavity, lips, peri-oral area, facial skin, hands or feet [3] [4].

These polyps are found in approximately $80 \%$ of the cases predominantly in the jejunum, followed by the ileum, the stomach and large intestine. Although Peutz-Jeghers polyps are most commonly found in the gastrointestinal system, they can also occur in other sites such as the kidney, ureter, gallbladder, bronchial tree, and nasal passages [5] [6].

Small bowel obstruction (by a sizable polyp), intussusception, bleeding and anemia are the major complications of this syndrome. The syndrome increases the risk of small bowel adenocarcinoma and is associated with other extra-intestinal malignancies, including cancers of the breast, pancreas, colon, female reproductive organs and testicular cancer [7] [8].

Diagnosis of intussusception can be delayed because of its longstanding, intermittent, and nonspecific symptoms, and most cases are diagnosed at emergency laparotomy subsequently requiring bowel resection and anastomosis [9].

Initial imaging studies are necessary in patients with suspected intussusception. The most common radiographic sign of an intussusception is a soft-tissue mass, usually located in the upper abdomen. At ultrasound (US), an intussusception may have a "doughnut" or "pseudo-kidney" appearance [10] [11]. Computed tomography (CT) findings are similar to those seen at US; it appears as a complex soft-tissue mass composed of a central intussusceptum and outer intussusception. The appearance of an intussusception on CT images is similar to that of a "target" mass when the X-ray beam is perpendicular to the longitudinal axis of the intussusception and to that of a "sausage" mass when the X-ray beam is parallel to the longitudinal axis [12].

The standard treatment for intussusception in patients with Peutz-Jeghers syndrome has been laparotomy and bowel resection to remove the underlying polyps causing the persistent or recurrent intussusceptions. However, some patients require multiple surgical resections, which can lead to short bowel syndrome. To avoid such complication, it has been recommended that endoscopy e.g. gastroscopy, colonoscopy, and double-balloon enteroscopy should be performed to remove all polyps [13] [14]. Also, during each laparotomy, the small bowel should be examined by means of intraoperative enteroscopy. This can 
help to eliminate gastrointestinal symptoms and prevent or postpone repeated abdominal surgeries [15].

Because of the increased risk of both gastrointestinal and extra-intestinal malignancies, careful screening of Peutz-Jeghers patients is recommended. Specific testing should include monitoring of hemoglobin levels, as well as regular breast, gynecologic, and testicular examinations. Pelvic, testicular, and pancreatic US screening should also be considered. Gastrointestinal tract screening can be performed with upper and lower endoscopy in combination with small bowel capsule endoscopy [16]. We designed this study to analyze the clinical characteristics, preoperative diagnosis, and surgical management of PJS associated-intussusception in adults.

\section{Patients and Methods}

In this study; we presented 5 cases with intussusception caused by Peutz-Jeghers syndrome who had presented to the Surgical Oncology Unit at General Surgery Department, Tanta University Hospital, Egypt and Hamad General Hospital, Hamad Medical Corporation, Qatar, between October 2011 and March 2016. The following data were collected: age, sex, family history of PJS, diagnosis of PJS, diagnosis and characteristics of intussusception, follow-up, morbidity and mortality. We included patients diagnosed with PJS on the basis of the diagnostic criteria of Giardiello et al. [5] that included: histopathological confirmation of Peutz Jeghers polyp according to World Health Organization [17] and at least two of the following criteria: family history of PJS, intestinal polyposis, and pigmented macules of buccal mucosa, lips, fingers, or toes.

Clinical findings of the 5 patients were collected from patients' charts, operative notes, and pathology reports. Intussusception characteristics that were recorded included date of diagnosis as well as data of presentation, localization, treatment, and size of the polyp causing the intussusception. Localization of the intussusception was classified as small or large intestinal based on the site of the leading point. The small intestinal intussusceptions were further subdivided according to the most proximal small intestinal segment involved.

Midline laparotomy was performed in all the cases with resection anastomosis of the bowel segment involved in the intussusception. The removed specimen was sent for histopathological examination. We only used the size of en bloc resected polyps, as measured by the pathologist, in order to get an objective measurement. A written consent for publication had been obtained from every patient included in the study. The study was approved by the ethical committee.

Case report 1 Female patient 33 years old presented with intermittent colicky abdominal pain for 3 days that had persisted for the last 5 hours. The maximum pain was in the periumbilical region. The patient also reported nausea and few episodes of non-bilious vomiting with no constipation. There was no known family history of Peutz-Jeghers syndrome. Physical examination revealed multiple pigmented spots on the face, both lips, and oral mucosa (Figure 1). On abdominal examination, upper abdominal and periumbilical tenderness was found. 


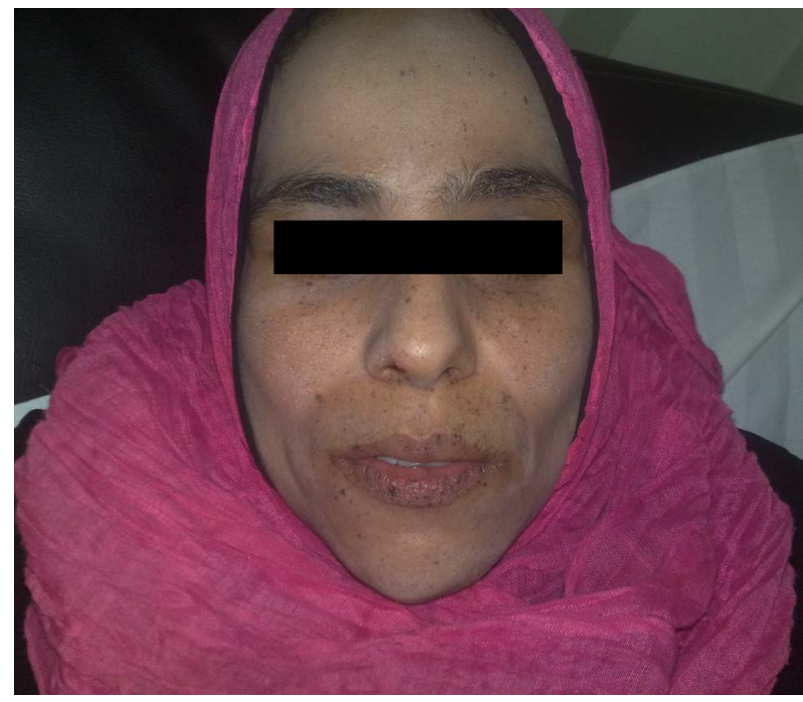

Figure 1. Multiple pigmented spots on the face and lips.

A tender epigastric mass was palpated with normal intestinal sounds. Laboratory investigations were unremarkable.

Radiological findings Abdominal X-ray demonstrated normal bowel gas pattern with no evidence of bowel obstruction or free air. Abdominal ultrasound showed a heterogeneous mass in the upper abdomen measured $6 \times 4 \mathrm{~cm}$. The mass had a "pseudokidney" appearance with central high echogenicity consistent with mesenteric fat within intussusception (Figure 2(a)). CT abdomen with oral and intravenous contrast demonstrated a large, complex soft-tissue mass measured $10 \times 4 \mathrm{~cm}$ in the umbilical and left lumbar region. The mass had two "doughnut" or "pseudokidney" appearances suggesting the diagnosis of double small bowel intussusceptions (Figure 2(b)).

Operative findings Double intussusceptions were found, the proximal one was jejunojejunal at $90 \mathrm{~cm}$ from the ligament of Treitz with a mass forming its lead point, and the second was jejunojejunal $15 \mathrm{~cm}$ distal to the first one (Figure $3(a))$. Reduction of the intussusceptions was done. Intestinal loops were viable and enterotomy over the lead point extruded a cauliflower polyp measured $3.5 \times$ $2.5 \mathrm{~cm}$ (Figure 3(b)). Resection anastomosis of this affected jejunal loop involved in this double intussusception was done. The patient had uneventful post-operative course.

Histopathological examination revealed branching muscular core formed of smooth muscles with a covering hyperplastic small intestinal mucosa that showed low grade dysplasia confirming the diagnosis of hamartomatous Peutz Jeghers polyp. The resection margins were free with no malignancy.

Case report 2 Female patient 42 years old presented to the emergency room with history of generalized abdominal pain for one day. The pain started in the upper abdomen. It was colicky in nature, radiated to the back and associated with repeated bilious vomiting and constipation. There was past history of small intestinal polypectomy through exploratory laparotomy since 20 years which proved to be Peutz-Jeghers hamartomatous polyp. The patient had positive fa- 


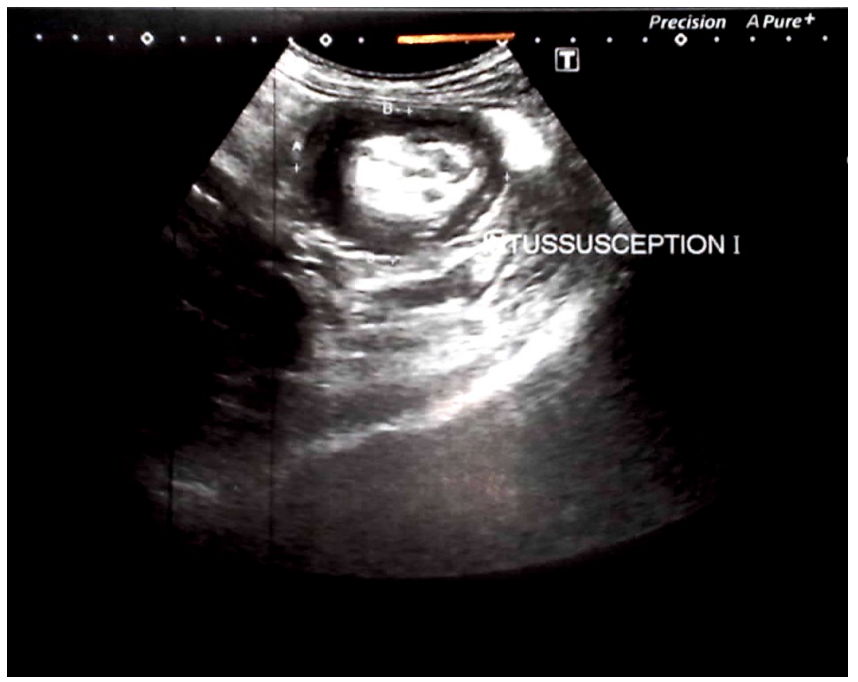

(a)

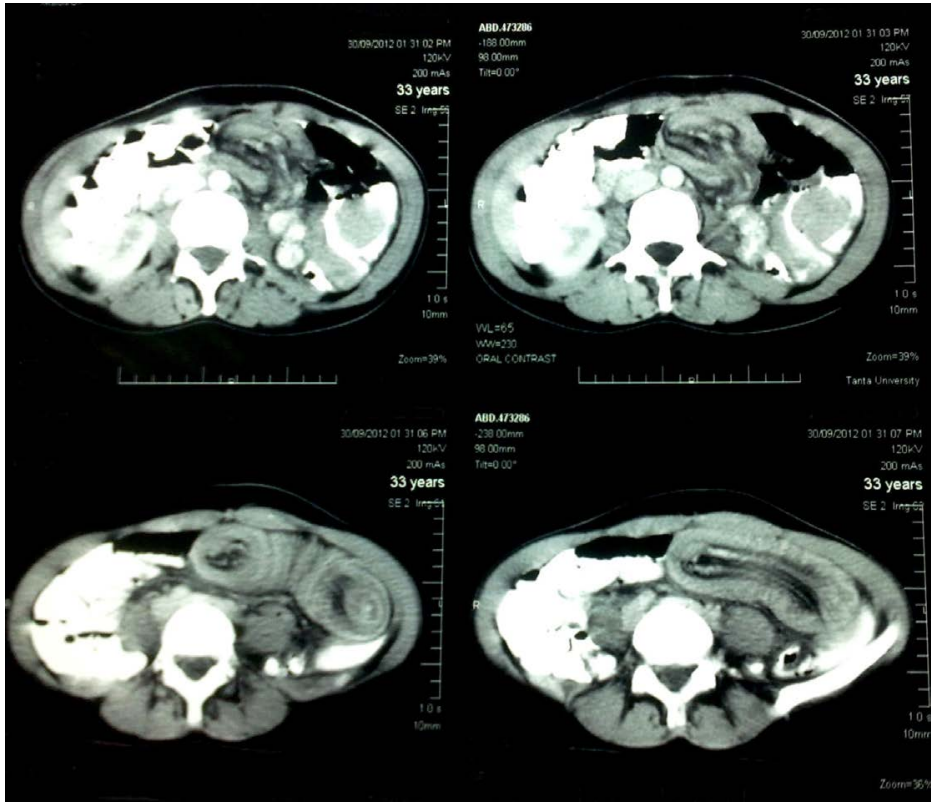

(b)

Figure 2. (a) Abdominal ultrasound showing "pseudokidney" appearance with central high echogenicity; (b) CT abdomen showing "pseudokidney" appearance (right) and two target signs (left).

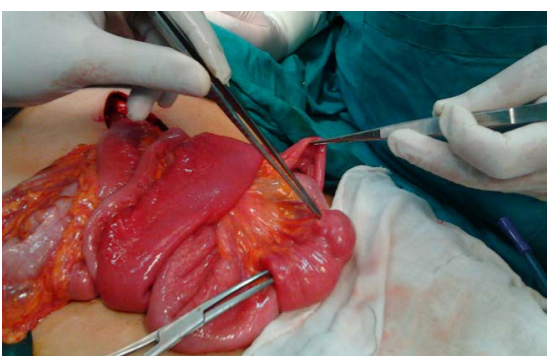

(a)

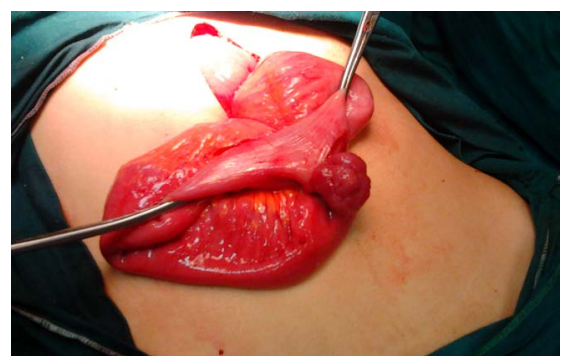

(b)

Figure 3. (a) The proximal intussusception, the polyp forming the lead point, and the distal intussusceptions; (b) The polyp extruded through enterotomy. 
mily history of Peutz-Jeghers syndrome. Physical examination revealed multiple pigmented lesions in the inner aspect of the lower lip and buccal mucosa (Figure 4). Abdominal examination showed mid-line laparotomy scar, tenderness all over the abdomen. There was palpable tender mass occupying the right iliac fossa with exaggerated intestinal sounds. Digital rectal examination showed blood stained loose stool. Laboratory investigations revealed leukocytosis, mild anemia, hypokalemia and hyponatremia. Plain abdominal X-ray demonstrated no evidence of bowel obstruction or free air. Abdominal ultrasound showed a "Target-like" lesion seen in right upper quadrant likely to suggest intussusception. CT abdomen demonstrated ileocecal intussusception with a polypoid mass at its tip with another jejunal intussusception.

At operation; double intussusceptions were found; the first was jejunojejunal at $120 \mathrm{~cm}$ from the ligament of Treitz and the second was ileocecal (Figure 5), with a mass forming the lead points of both intussusceptions. Reduction of the first intussusception was done. Intestinal loops were viable with a palpable mass in the affected loop. Resection anastomosis was done. The resected loop was opened and it showed cauliflower polyp measured $4 \times 3 \mathrm{~cm}$. Right hemicolec-

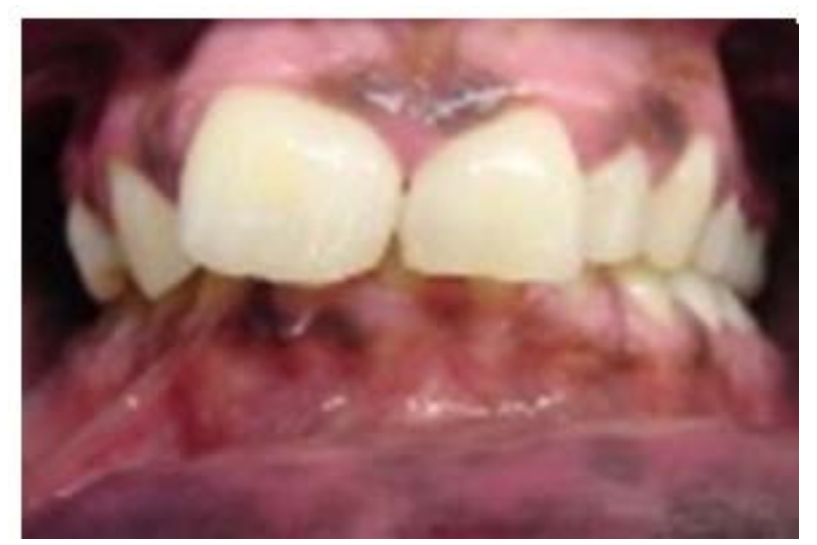

Figure 4. Multiple pigmented patches in the inner surface of the lower lip and gums.

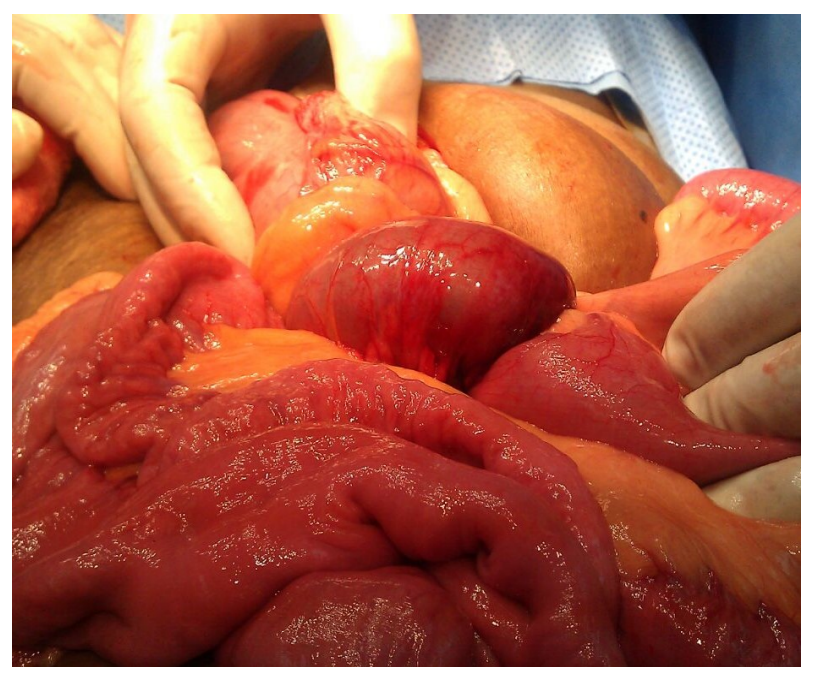

Figure 5. Ileocecal intussusceptions. 
tomy with ileo-transverse anastomosis was done for the second intussusception that contained a large polypoid mass $5 \times 4 \mathrm{~cm}$ at the terminal ileum $5 \mathrm{~cm}$ proximal to the ileocecal valve. The patient had a smooth post-operative course. Histopathological examination confirmed the diagnosis of hamartomatous Peutz Jeghers polyps with no malignancy.

Case report 3 Male patient 21 years old presented with intermittent colicky periumbilical abdominal pain since 5 days that persisted for the last few hours associated with bilious vomiting with no constipation. There was no known family history of Peutz-Jeghers syndrome. Physical examination revealed multiple pigmented lesions in lips, face and fingers of both hands. Abdominal examination showed mild periumbilical tenderness with no palpable masses and normal intestinal sounds. Laboratory data showed leukocytosis and mild anemia. Plain abdominal X-ray demonstrated no evidence of bowel obstruction or free air. Abdominal ultrasound showed a "Target-like" lesion seen in the mid-abdomen likely to suggest intussusception (Figure 6(a)). CT scan of the abdomen demonstrated an ileoileal intussusception. Intra-operatively; an ileoileal intussusception was found at $150 \mathrm{~cm}$ proximal to the ileocecal valve with a mass forming the lead point. Reduction of the intussusception was successful, intestinal loops were viable. Resection anastomosis of the ileal loop was done. It showed presence of $3 \times 3 \mathrm{~cm}$ polyp. Histopathological examination confirmed the diagnosis of hamartomatous Peutz-Jeghers polyp with no malignancy (Figure 6(b)). The patient had a smooth post-operative course with no complications.

Case report 4 Female patient 28 years old presented with intermittent colicky upper abdominal pain for two days associated with bilious vomiting with no constipation. No known family history of Peutz-Jeghers syndrome. Physical examination revealed that the patient was dehydrated with multiple pigmented lesions in the oral cavity and face. Abdominal examination showed upper abdominal guard and tenderness. There was palpable upper abdominal sausage shaped mass with slight exaggerated intestinal sounds. Laboratory investigations revealed mild hypokalemia and hyponatremia. Plain abdominal X-ray demonstrated no evidence of bowel obstruction or free air. Abdominal ultrasound showed a "Target-like" lesion seen in left upper quadrant likely to suggest in-

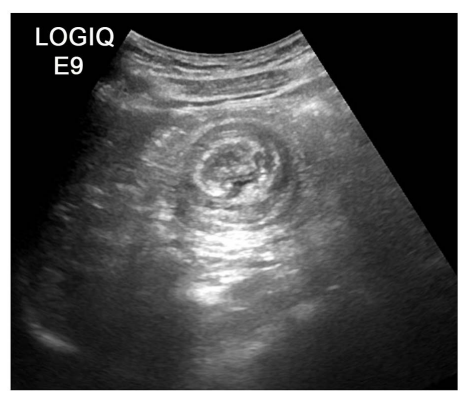

(a)

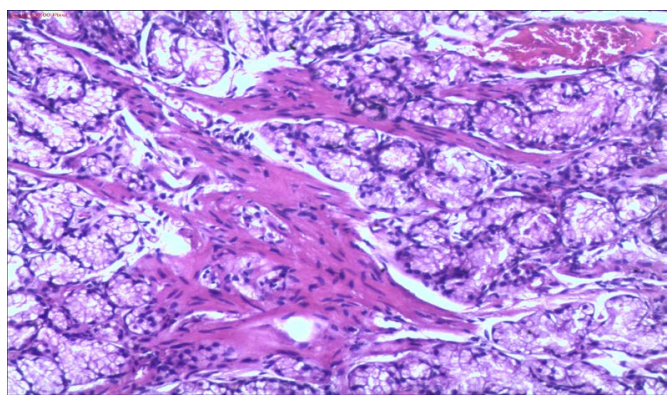

(b)

Figure 6. (a) US showing the "Target-like" lesion of intussusceptions; (b) Hamartomatous polyp showing branching muscular core formed of smooth muscles with covering hyperplastic mucosa $(\mathrm{H} \& \mathrm{E} \times 200)$. 
tussusception which proved to be jejunojejunal by CT scan (Figure 7(a)). Intraoperatively; a jejunojejunal intussusception (Figure 7(b)) was found at $150 \mathrm{~cm}$ from the dudenojejunal junction with a mass forming the lead point. Reduction of the intussusception was successful and intestinal loops were viable. Resection anastomosis of the involved jejunal loop was done. A cauliflower polyp measured $3.53 \times .5 \mathrm{~cm}$ was found in the resected loop. The patient had a good post operative course. Histopathological examination revealed benign hamartomatous Peutz-Jeghers polyp.

Case 5 Male patient 18 years old presented with intermittent colicky upper abdominal pain that increased for the last day. No vomiting or constipation. The patient had positive family history of PJS. On examination, there were multiple pigmented lesions in the lips and fingers. Upper abdominal tenderness was found with no palpable masses. Laboratory investigations showed mild leukocytosis and anemia. Plain X-ray did not show any evidence of intestinal obstruction. Abdominal US and CT scan showed a target like lesion in the upper abdomen suggestive of jejunojejunal intussusception. Mid-line laparotomy was done that showed a jejunojejunal intussusception $80 \mathrm{~cm}$ from the dudenojejunal flexure with a mass forming the lead point and no gangrene. Reduction of the intussusception was successfully done with resection of the affected segment that showed presence of $2 \times 2.5 \mathrm{~cm}$ polyp. This polyp was proved to be hamartomatous Peutz-Jeghers polyp on pathological examination (Figure 8).

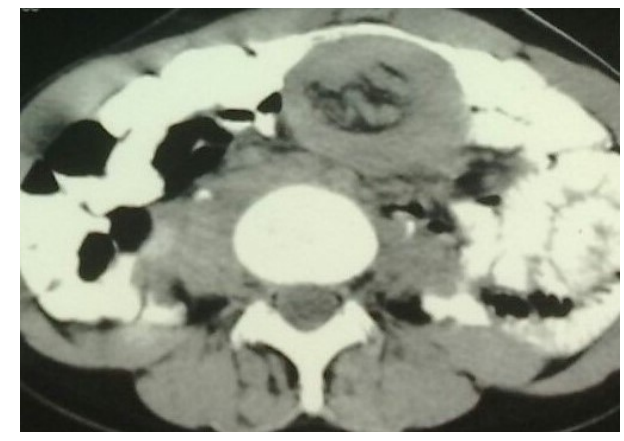

(a)

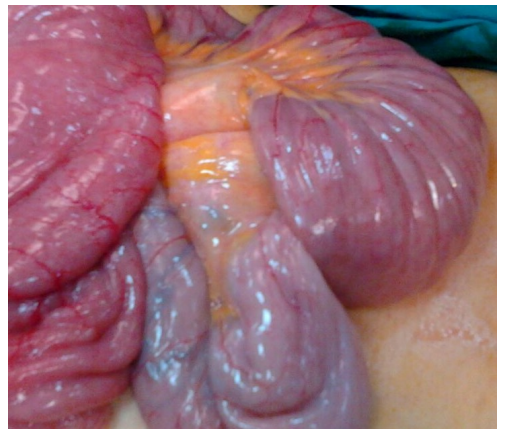

(b)

Figure 7. (a) CT scan showing jejunojejunal intussusception with "Target sign"; (b) Intra-operative finding of jejunojejunal intussusception.

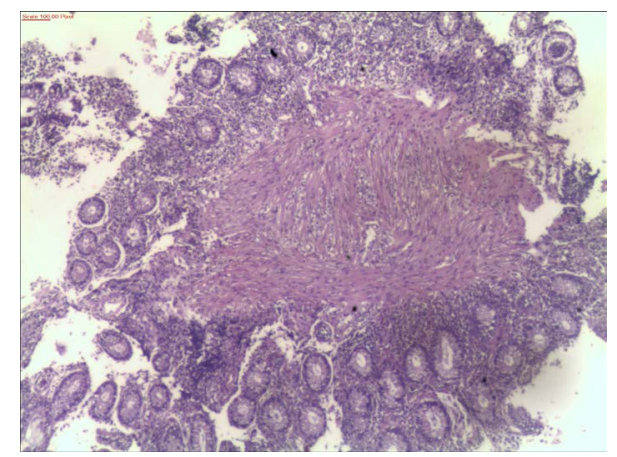

Figure 8. Hamartomatous polyp showing a smooth muscular core with a covering hyperplastic mucosa $(\mathrm{H} \& \mathrm{E} \times 200)$. 
All the patients were seen in the outpatient clinic 2 weeks and 1 month postoperatively. Then, they were seen each 6 months. On each visit, regular abdominal, breast, gynecologic, and testicular examinations were performed. Abdomino-pelvic US (and CT scan if needed), testicular US, breast US (for females), hemoglobin, \& tumor markers (CEA, CA19.9, CA 15.3, AFP and CA125) levels were done each 6 months. Mammography was done yearly for female patients (above 35 years old). Gastrointestinal tract screening was performed with yearly upper and lower GI endoscopy with endoscopic removal of any polyps found.

\section{Results}

\subsection{Patients' Demographics}

A total of 5 patients with PJS were included in this study. The patients' age ranged from 18 to 42 years old, with a mean age of 28.4 years. Female predominated with a female: male ratio of 3:2. Case 2 had a prior laparotomy for a previous intussusception and small intestinal polypectomy. Two patients had a positive family history of PJS (Table 1).

\subsection{Clinical and Radiological Findings}

The different clinical manifestations were illustrated in Table 1. All the patients had pigmented spots in different sites and numbers. The spot diameter ranged between 2 and $5 \mathrm{~mm}$.

Pain was the most common presenting complaint with or without manifestations of intestinal obstruction. Palpable abdominal mass was found in 3 out of 5

Table 1. Patients' characteristics.

\begin{tabular}{cc}
\hline Age (years): & No (\%): \\
Less than 40 & $4(80)$ \\
More than 40 & $1(20)$ \\
\hline Gender: & No (\%): \\
Female & $3(60)$ \\
Male & $2(40)$ \\
\hline Family History: & No (\%): \\
Positive & $2(40)$ \\
Negative & $3(60)$ \\
\hline Clinical Manifestations: & No (\%): \\
Abdominal pain & $5(100)$ \\
Bilious vomiting & $3(60)$ \\
Constipation & $1(20)$ \\
Abdominal mass & $3(60)$ \\
Hematochezia & $1(20)$ \\
\hline & \\
\hline &
\end{tabular}


patients (60\%). One patient (case no. 2) had abdominal pain along with hematochezia.

Intussusception was a preoperative diagnosis in $100 \%$ of patients (Table $2 \&$ Table 3). In all the cases, plain abdominal X-ray, abdominal ultrasound and abdominal CT had been performed. Because plain X-ray was not able to demonstrate the intussusception, abdominal ultrasound and CT scan were done. They provided the diagnosis of intussusception and identified the nature of the underlying pathology with a sensitivity rate of $100 \%$ (Table 2 ).

\subsection{Operative Results}

The polyps varied in type, size, location, and number (Table 3). Among 5 patients with intussusception; localization of polyps was classified as jejunal in 3 patient, ileal in 1 patient, and both jejunal and ileal in 1 patient.

Different types of intussusception were analyzed in Table 3. The choice of surgical procedure was determined by location, size, cause, and viability of the bowel. All patients had a laparotomy and a successful manual reduction of the intussusception that was followed by resection anastomosis of the bowel loop containing the hamartomatous polyp. Histopathological study reported the presence of typical Peutz-Jeghers polyp that showed branched proliferation of hyperplastic glandular cells with a core of smooth muscles. Only 1 case (case no. 1) showed low grade dysplasia. No malignancy was detected in all the specimens. No postoperative complications were reported.

\subsection{Follow Up}

The follow up period ranged from 61 to 8 months with a mean of 32 months. During this period, all the patients had no complaints, no clinical abnormality was detected and follow up investigations were unremarkable (Table 3).

Table 2. Preoperative radiological examination.

\begin{tabular}{ccc}
\hline Procedure & No. of Patients & Accuracy (\%) \\
\hline Plain X-ray of the abdomen & 5 & 0 \\
Abdominal ultrasound & 5 & 100 \\
Abdominal CT scan & 5 & 100 \\
\hline
\end{tabular}

Table 3. Radiological and operative findings.

\begin{tabular}{ccccccccc}
\hline Case & $\begin{array}{c}\text { Pre-operative } \\
\text { diagnosis }\end{array}$ & $\begin{array}{c}\text { Previous } \\
\text { surgery }\end{array}$ & Type of intussuscept-ion & $\begin{array}{c}\text { Location } \\
\text { of polyps }\end{array}$ & $\begin{array}{c}\text { Polyp size } \\
(\mathrm{cm})\end{array}$ & $\begin{array}{c}\text { Surgical } \\
\text { treatment }\end{array}$ & Cancer & Follow-up \\
\hline 1 & Yes/US \& CT & NO & Double Jejunojejunal & Jejunum & $2.5 \times 3.5$ & Resection/anastomosis & NO & 61 months \\
2 & Yes/US \& CT & Yes/laparotomy & Jejunojejunal \& ileocecal & $\begin{array}{c}\text { Jejunum } \\
\text { and ileum }\end{array}$ & $\begin{array}{c}3 \times 4 \\
4 \times 5\end{array}$ & Resection/anastomosis & NO & 42 months \\
3 & Yes/US \& CT & NO & Ileoileal & Ileum & $3 \times 3$ & Resection/anastomosis & NO & 34 months \\
4 & Yes/US \& CT & NO & Jejunojejunal & Jejunum & $3.5 \times 3.5$ & Resection/anastomosis & NO & 15 months \\
5 & Yes/US \& CT & NO & Jejunojejunal & Jejunum $\times$ & $2 \times 2.5$ & Resection/anastomosis & NO & 8 months \\
\hline
\end{tabular}




\section{Discussion}

Peutz-Jeghers syndrome (PJS) is a rare autosomal dominant disorder resulting from mutation of the serine/threonine kinase 11 which is a tumor suppressor gene located on chromosome 19p13.3 [18]. It is estimated that about half of the patients with PJS will have intussusception; because of the large size of the polyps and its pedunculated nature, that requires surgery. They may also show recurrent intussusception that needs repeated operations [19] [20] [21]. Early diagnosis of PJS associated with intussusception is important to allow for early intervention and to prevent further complications [22] [23]. Including symptoms of intussusception, there are at least two of the following clinical criteria that should be present: a family history of the syndrome, melanin deposits, and bowel polyposis [5].

In the current study; a total of 5 patients with PJS were included for analysis. The patients' age ranged from 18 to 42 years with a mean age of 28.4 years. Female predominated with a female: male ratio of 3:2. These results are in accordance with the results of Hong et al. [24] who studied 11 patients with PJS and intussusception, the patients' age ranged from 19 to 67 years with a mean age of 31.7 years. Female predominated in a ratio of 2.7:1. In another study by Jeghers et al. [3], they studied 9 patients with PJS associated intussusception. They reported that the patients' age ranged from 9 to 39 years with a mean of 20.8 years old. Female predominated with a female to male ratio of 3.5:1.

The mucocutaneous pigmentations caused by melanin aggregation can be seen in $93 \%$ of patients even in infancy. They are generally located around the lips, buccal mucosa, hands, feet, and sometimes perianal and genital areas [25]. The clinical presentations of adult intussusception are widely variable depending on the site of the intussusception and the possibility of self reduction. The symptoms can range from mild abdominal pain to more acute signs of intestinal obstruction. The classic triad of abdominal pain, palpable abdominal mass and red currant jelly stool is not found in all the patients with PJS associated intussusception. So, complete family history and physical examination including identification of the mucocutaneous pigmentations are very important in diagnosing acute intussusceptions caused by PJS because there is no obvious difference between PJS associated intussusception and ordinary intussusception in other clinical manifestations [26].

Conventional barium studies have been replaced nowadays by non-invasive cross-sectional techniques, such as ultrasonography and CT scan which not only improve visualization of the intestinal lumen, but also detect intestinal wall and extraluminal diseases. Intussusception may represent a "target mass" on both CT scan and ultrasound. More importantly, CT scan may help to delineate the precise location of the polyps because differentiating between lead point and nonlead point intussusception is important in determining the appropriate treatment and has the potential to reduce the prevalence of unnecessary surgery [27] [28].

In our study; all the patients had pigmented spots in different sites and num- 
bers with a diameter ranged from 2 to $5 \mathrm{~mm}$. Two patients (40\%) had a positive family history of PJS. Pain was the most common presenting complaint (in 100\% of the patients). One patient (20\%) had constipation and one patient (20\%) had hematochezia. Palpable abdominal mass was found in 3 out of 5 patients (60\%). Intussusception was diagnosed pre-operatively in $100 \%$ of patients. Abdominal CT scan provided the diagnosis of intussusception and identified the nature of the underlying pathology with a sensitivity rate of $100 \%$. This agrees with Hong et al. [24] who found that the spot diameter was between 2 and $5 \mathrm{~mm}$. All the patients presented with an acute abdomen. Palpable abdominal mass was found in $72.7 \%$ of the patients. Fifty four percent of the patients had abdominal pain along with constipation. Hematochezia was found in $27 \%$ of the patients. CT scan proved the preoperative diagnosis in $100 \%$ of cases.

In the present study; all the polyps were located in the small intestine (3 jejunal, one ileal and one combined ileal and jejunal). This coincides with a collective case series reported from the Mayo Clinic in which $96 \%$ of the patients had small bowel polyps [2] [29].

Definitive surgical resection remains the recommended treatment in most of the cases of PJS associated with intussusception because of the large proportion of structural causes and to exclude the possibility of malignancy [30]. The choice of the procedure was determined by the location, size, cause, and viability of the bowel. In the current study, all the patients had a laparotomy. We tried the intraoperative manual reduction of intussusception which was successful in all the cases to achieve a limited bowel resection. To avoid the possibility of missing any malignancy; conventional resection and anastomosis of the involved bowel segment rather than polypectomy was done in all the cases. No postoperative complications were reported. These results are consistent with Hong et al. [24] who studied 11 PJS patients with intussusception. All of them had a laparotomy with successful manual reduction of the intussusception. Eight patients underwent intestinal resection and anastomosis, while 2 patients underwent only polypectomy. One patient underwent intestinal resection with ileostomy. None of the patients suffered any postoperative complication.

Intraoperative endoscopy (IOE) is a combination of laparotomy and endoscopy, which was accepted as the ultimate diagnostic and/or therapeutic procedure that allows the surgeon to visualize the entire small bowel and to remove nearly all the polyps [31], but unfortunately, IOE was not available in our hospital.

\section{Conclusion}

In conclusion, different clinical manifestations of intussusception can be seen in patients with Peutz-Jeghers syndrome. Family history and physical examination are important in diagnosing PJS associated intussusception. CT scan with or without ultrasonography is considered the most accurate diagnostic tool for acute intussusceptions caused by PJS. Surgical management of PJS associated intussusception is the recommended treatment to relieve patient's symptoms and to avoid missing any underlying malignancy. Patients with PJS should be 
followed up throughout their lives because of the increased risk of malignant changes and to reduce the number of laparotomies and shortening of the bowel.

\section{References}

[1] Rebsdorf, P.I., Hartvigsen, A., Fischer, H.B., Toftgaard, C., Konstantin-Hansen, K. and Bullow, S. (1994) Management of Peutz-Jeghers Syndrome: Experience with Patients from the Danish Polyposis Register. International Journal of Colorectal Disease, 9, 177-179. https://doi.org/10.1007/BF00292244

[2] Bartholomew, L.G., Moore, C.E. and Dahlin, D.C. (1962) Intestinal Polyposis Associated with Mucocutaneous Pigmentation. Surgery, Gynecology \& Obstetrics, 115, $1-11$.

[3] Jeghers, H.., McKusick, V.A. and Katz, K.H. (1949) Generalized Intestinal Polyposis and Melanin Spots of the Oral Mucosa, Lips and Digits: A Syndrome of Diagnostic Significance. New England Journal of Medicine, 241, 1031-1036. https://doi.org/10.1056/NEJM194912292412601

[4] Peutz, J.L.A. (1921) A Very Peculiar Familial Polyposis of the Mucous Membrane of the Digestive Tract and the Nasopharynx Together with Peculiar Pigmentation of the Skin and Mucous Membrane. Nederl Maandschr v Geneesk, 10, 134-146.

[5] Giardiello, F.M. and Trimbath, J.D. (2006) Peutz-Jeghers Syndrome and Management Recommendations. Clinical Gastroenterology and Hepatology, 4, 408-415. https://doi.org/10.1016/j.cgh.2005.11.005

[6] Latchford, A., Greenhalf, W., Vitone, L.J. and Neoptolemos, J.P. (2006) PeutzJeghers Syndrome and Screening for Pancreatic Cancer. British Journal of Surgery, 93, 1146-1455. https://doi.org/10.1002/bjs.5609

[7] Wirtzfeld, D.A., Petrelli, N.J. and Rodriguez-Bigas, M.A. (2001) Hamartomatous Polyposis Syndromes; Molecular Genetics, Neoplastic Risk, and Surveillance Recommendations. Annals of Surgical Oncology, 8, 319-327.

https://doi.org/10.1007/s10434-001-0319-7

[8] Van Lier, M.G.F., Wagner, A. and Mathus-Vliegen, E.M.H. (2010) High Cancer Risk in Peutz-Jeghers Syndrome: A Systematic Review and Surveillance Recommendations. The American Journal of Gastroenterology, 105, 1258-1264. https://doi.org/10.1038/ajg.2009.725

[9] Tabrizian, P., Nguyen, S.Q., Greenstein, A., Rajhbeharrysingh, U., Argiriadi, P., Barlow, M., Chao, T.E. and Divino, C.M. (2010) Significant Parameters for Surgery in Adult Intussusception. Surgery, 147, 227-232. https://doi.org/10.1016/j.surg.2009.09.036

[10] Del-Pozo, G., Albillos, J.C., Tejedor, D., Calero, R. and Rasero, M. (1999) Intussusception in Children: Current Concepts in Diagnosis and Enema Reduction. RadioGraphics, 19, 299-319. https://doi.org/10.1148/radiographics.19.2.g99mr14299

[11] Swischuk, L.E., Hayden, C.K. and Boulden, T. (1985) Intussusception Indications for Ultrasonography and/or Explanation of the Doughnut and Pseudokidney Signs. Pediatric Radiology, 15, 388-391. https://doi.org/10.1007/BF02388356

[12] Gayer, G., Hertz, M. and Zissin, R. (2003) CT Findings of Intussusceptions in Adults. Seminars in Ultrasound, CT, and MRI, 24, 377-386. https://doi.org/10.1016/S0887-2171(03)00073-8

[13] Matsumoto, Y., Manabe, N. and Tanaka, S. (2006) Small Intestinal Peutz-Jeghers Polyps Resected by Double Balloon Enteroscopy and Removal Confirmed by Ultrasonography. Digestive Diseases and Sciences, 51, 2337-2340. https://doi.org/10.1007/s10620-006-9381-0 
[14] Ohmiya, N., Taguchi, A. and Shirai, K. (2005) Endoscopic Resection of PeutzJeghers Polyps throughout the Small Intestine at Double Balloon Endoscopy without Laparotomy. Gastrointestinal Endoscopy, 61, 140-147. https://doi.org/10.1016/S0016-5107(04)02457-5

[15] Panos, R.G., Opelka, F.G. and Nogueras, J.J. (1990) Peutz-Jeghers Syndrome: A Call for Intraoperative Enteroscopy. The American Journal of Surgery, 56, 331-333.

[16] Rufener, S.L., Khaldoun, K., McKenna, B.J. and Michael, W. (2008) Small Bowel Intussusception Secondary to Peutz-Jeghers Polyp. Radiographic, 28, 284-288. https://doi.org/10.1148/rg.281075092

[17] Aaltonen, L.A., Jarvinen, H. and Gruber, SB. (2000) Peutz-Jeghers Syndrome. In: Hamilton, S.R. and Aaltonen, L.A., Eds., World Health Organization Classification of Tumours. Pathology and Genetics of Tumours of the Digestive System, IARC Press, Lyon, 72-76.

[18] Jamaludin, A.Z., Telisinghe, P.U., Yapp, S.K. and Chong, V.H. (2009) Solitary Duodenal Hamartomatous Polyp with Malignant Transformation: Report of a Case. Surgery Today, 39, 527-532. https://doi.org/10.1007/s00595-008-3873-9

[19] McGarrity, T.J., Kulin, H.E. and Zaino, R.J. (2000) Peutz Jeghers Syndrome. The American Journal of Gastroenterology, 95, 596-604. https://doi.org/10.1111/j.1572-0241.2000.01831.x

[20] Utsunomiya, J., Gocho, H., Miyanaga, T., Hamaguchi, E. and Kashimure, A. (1975) Peutz-Jeghers Syndrome: Its Natural Course and Management. The Johns Hopkins Medical Journal, 136, 71-82.

[21] Foley, T.R., McGarrity, T.J. and Abt, A.B. (1988) Peutz-Jeghers Syndrome: A Clinicopathologic Survey of the "Harrisburg Family" with a 49-Year Follow-Up. Gastroenterology, 95, 1535-1540. https://doi.org/10.1016/S0016-5085(88)80074-X

[22] Baeza-Herrera, C., Garcia-Cabello, L.M., Najera-Garduno, H.M., Sanchez-Fernandez, L.A., Mora-Hernandez, F. and Ortiz-Zuniga, A.I. (2005) Surgical Aspects of Intussusception Secondary to Peutz-Jeghers Syndrome. Cirugía y Cirujanos, 73, 9195.

[23] Van Lier, M.G., Mathus-Vliegen, E.M., Wagner, A., van Leerdam, M.E. and Kuipers, E.J. (2011) High Cumulative Risk of Intussusception in Patients with Peutz-Jeghers Syndrome: Time to Update Surveillance Guidelines? The American Journal of Gastroenterology, 106, 940-945. https://doi.org/10.1038/ajg.2010.473

[24] Wang, H., Luo, T., Liu, W.-Q., Huang, Y., Wu, X.-T. and Wang, X.-J. (2011) Clinical Presentations and Surgical Approach of Acute Intussusception Caused by Peutz-Jeghers Syndrome in Adults. Journal of Gastrointestinal Surgery, 15, 22182225. https://doi.org/10.1007/s11605-011-1724-2

[25] Higham, P., Alawi, F. and Stoopler, E.T. (2010) Medical Management Update: Peutz-Jeghers Syndrome. Oral Surgery, Oral Medicine, Oral Pathology, Oral Radiology, 109, 5-11. https://doi.org/10.1016/j.tripleo.2009.08.022

[26] Lantz, H., Doos, W.G. and Affi, A. (2004) Peutz-Jeghers-Type Hamartomatous Polyp in a Patient without Peutz-Jeghers Syndrome. Gastrointestinal Endoscopy, 60, 316-317. https://doi.org/10.1016/S0016-5107(04)01563-9

[27] Dean, A.J., Lafferty, K. and Villanueva, T.C. (2003) Emergency Medicine Bedside Ultrasound Diagnosis of Intussusception in a Patient with Chronic Abdominal Pain and Unrecognized Peutz-Jeghers Syndrome. The Journal of Emergency Medicine, 24, 203-210. https://doi.org/10.1016/S0736-4679(02)00726-6

[28] Kim, Y.H., Blake, M.A., Harisinghani, M.G., Archer-Arroyo, K., Hahn, P.F., Pitman, M.B. and Mueller, P.R. (2006) Adult Intestinal Intussusception: CT Appear- 
ances and Identification of a Causative Lead Point. Radiographics, 26, 733-744. https://doi.org/10.1148/rg.263055100

[29] Bartholomew, L.G., Dahlin, D.C. and Waugh, J.M. (1957) Intestinal Polyposis Associated with Mucocutaneous Melanin Pigmentation Peutz-Jeghers Syndrome; Review of the Literature and Report of Six Cases with Special Reference to Pathologic Findings. Gastroenterology, 32, 434-451.

[30] Van Lier, M.G., Westerman, A.M., Wagner, A., Looman, C.W., Wilson, J.H., de Rooij, F.W., Lemmens, V.E., Kuipers, E.J., Mathus-Vliegen, E.M. and van Leerdam, M.E. (2011) High Cancer Risk and Increased Mortality in Patients with PeutzJeghers Syndrome. Gut, 60, 141-147. https://doi.org/10.1136/gut.2010.223750

[31] Beggs, A.D., Latchford, A.R., Vasen, H.F., Moslein, G., Alonso, A., Aretz, S., Bertario, L., Blanco, I., Bulow, S., Burn, J., Capella, G., Colas, C., Friedl, W., Moller, P., Hes, F.J., Jarvinen, H., Mecklin, J.P., Nagengast, F.M., Parc, Y., Phillips, R.K., Hyer, W., Ponz, D.L.M., Renkonen-Sinisalo, L., Sampson, J.R., Stormorken, A., Tejpar, S. Thomas, H.J., Wijnen, J.T., Clark, S.K. and Hodgson, S.V. (2010) Peutz-Jeghers Syndrome: A Systematic Review and Recommendations for Management. Gut, 59, 975-986. https://doi.org/10.1136/gut.2009.198499

\section{Submit or recommend next manuscript to SCIRP and we will provide best service for you:}

Accepting pre-submission inquiries through Email, Facebook, LinkedIn, Twitter, etc. A wide selection of journals (inclusive of 9 subjects, more than 200 journals)

Providing 24-hour high-quality service

User-friendly online submission system

Fair and swift peer-review system

Efficient typesetting and proofreading procedure

Display of the result of downloads and visits, as well as the number of cited articles

Maximum dissemination of your research work

Submit your manuscript at: http://papersubmission.scirp.org/

Or contact ss@scirp.org 